\title{
Anonymity Feature in Android Mobile Apps for Interest Groups
}

\author{
Lee Sin $\mathrm{Yi}^{1}$, Nurul A. Emran ${ }^{2}$, Norharyati Harum ${ }^{3}$ \\ Fakulti Teknologi Maklumat dan Komunikasi, \\ Universiti Teknikal Malaysia Melaka, \\ Malaysia
}

\begin{abstract}
Mobile apps that provide platforms for interestoriented communities (or interest groups) allow people with common interests to gather virtually in sharing their shared passion and ideas. While the participation of such apps is voluntary, some people feel uncomfortable revealing their real identities due to privacy and safety concerns. Thus, some mobile apps provide an anonymity feature that allows people to join the group anonymously. Nevertheless, little is known on how the anonymity feature relates to the people who prefer to join interest groups. Thus in this paper, we hypothesize that mobile apps users that highly value interest groups will also highly appreciate the anonymity feature provided in the interest groups. In particular, we explored the market segment of mobile Android apps with anonymity features within selected interest groups. A pilot study was conducted where 34 Android apps users, primarily Malaysian, filled up the questionnaires designed to investigate the anonymity feature in the apps. The results of the pilot study show that most Android apps nowadays offer their users to remain anonymous. The findings show that most users who give a high score on the importance of interest-based groups also provide a high score on the importance of the anonymity feature offered by the mobile apps providers.
\end{abstract}

Keywords-Anonymity feature; mobile social apps; quantitative observation; android apps; anonymous social media; interest groups component

\section{INTRODUCTION}

Online communities are often connected to common interest communities voluntarily. The advantage of online communities is that there will be no face-to-face or physical access requirements. With the interest-based groups that can be accessed through mobile apps, more people can easily find new friends with similar interests. The so-called social apps are not limited to the young generation and have become more popular among the elders [1]. For example, people who are fond of hiking can find other people with similar interests in the hiking-interest community from mobile apps.

Furthermore, with the proliferation of interest-oriented mobile apps such as Meetup, Smactive, WeGoDo, the mobile apps users community can connect with people with a similar passion more than ever before [2]. Major social media apps platforms like Facebook, Whatsapp, and Telegram also provide accessible platforms for interest group creations. Martin, in 2019 reported that marketers could use interest-based groups in Facebook to boost their product sales against the targeted audience [3], which is an indication of the potential of interestbased groups from a marketing perspective.
Facebook keeps profiles of its users' interests based on users' behavior, such as the pages a user likes, the previous ads they clicked, the websites and posts they engaged. For example, we can see various interest-based categories and subcategories if we utilize Facebook's ads manager platform. An 'interest' category like Hobbies and activities has several subcategories such as Arts and music, Home and garden (Furniture, Gardening, Do it yourself (DIY)).

Within the interest groups, the members usually seek to exchange information or ideas on specific topics or get solutions for their problems. Participation in an interest group can be entertaining, compelling and people often return and stay active for an extended period. Most of the time, these people cannot be defined by a specific geographical area. Without knowing each other's real identity, everyone will have equal rights and freedom to express their minds. Selfdisclosure can help in releasing stress and pressure, satisfying needs, and adapting communications behaviors [4].

As the identity of the members is usually being disclosed, there is a rising concern about the privacy and confidentiality of the members. Thus, the anonymity topic has become a focus in many application domains [3]-[8], and a new type of social media apps called anonymous social media has emerged [9]. Anonymous apps (such as Secret and Yik Yak) gain popularity because many people want to express themselves freely [10]. Such apps also become a 'tree hole' (confidant) where people can share their problems anonymously. The actual name and information of the app users will not be made compulsory during the registration process. In this way, people will share the problems that they do not want their family and close friends to know. Help or guidance from the other members can be received without the pressure of being judged by the people who do not know them personally. People with low self-esteem especially suffer the most when it comes to identity disclosure [11]. Besides, in research conducted by Ma, Hancock, and M. Naaman (2016), they found that people tend to minimize selfdisclose as content intimacy increases [4].

In online platforms, people usually tend to express themselves more openly. They can share the things that they will not share in the face-to-face world as they feel more uninhibited in cyberspace. From the psychological perspective, this is being called the disinhibition effect by the researchers [12]. People tend to align their virtual identity with their selfguide when reconstructing a new identity in an anonymous application. The self-discrepancy between their self-guided and

This work is sponsored by the Universiti Teknikal Malaysia Melaka under research grant PJP/2020/FTMK/PP/S01771 
virtual identity will be lesser as they will show more true selves with the latest online identity [12].

They may be more satisfied and motivated to show their true self freely without much constraint in an anonymous community online. According to Suler (2004), when people tend to show more generosity and kindness without their real identity being known by people, this is called benign disinhibition. However, there may be toxic disinhibition in the form of rude language or harsh criticisms [13], which lead to cyberbully. Denzil et al. (2015) divide anonymity based on the sensitivity level of the social media contents where anonymity is beyond the binary concepts of anonymous or nonanonymous types [9].

As there is a call for mobile apps that subscribe for anonymity feature, in this paper, we are motivated to answer the following research questions:

a) What is the proportion of the market segment for mobile apps with anonymity features in interest groups understudy?

b) How perception of the importance of interest group relates to the perception of the anonymity feature?

In the next section, related work on the anonymity feature will be presented. Section III consists of the methods used to answer the research questions; Section IV covers the findings and discussion. Finally, Section V concludes the research.

\section{RELATED WORK}

There is a $13.4 \%$ increase in the number of social app downloads from the Google Play Store from the year 2019 to 2020, which makes 1.18 billion downloads in 2020 [14]. On average, people spent 131 minutes every week on the Social app, which is the most extended amount of time spent within the mobile apps category. Gaming, Communication, and Music are also among the top apps category in time spent statistics. Facebook is the most popular social media platform worldwide, with 2.6 billion users, as of July 2020, followed by YouTube and Whatsapp [14].

A survey conducted from September 2016 to January 2021 revealed that 86 percent of Malaysians were actively engaged with social media. Facebook was the most popular social media platform of choice among Malaysian, followed by Instagram, Facebook Messenger, and LinkedIn [15].

The popularity of Facebook might be driven by its flexibility in creating and joining interest-based groups. In Facebook, a Facebook Group feature allows the creation of interest-based groups for its members to communicate, express their minds, and share their mutual interests or passion [16][17]. Facebook allows Facebook users to join up to 6000 groups at the same time. One requirement set by Facebook is the real-name policy, where Facebook users must use their real name to register a Facebook account and configure the user's profile. This is a compulsory requirement for all Facebook users. Through this method, the real-name policy will ensure the safety of the group members as one will know about the identity of the persons they are connecting with.
A "real name" refers to the actual name in this policy as it would be shown on the identity card, student ID, driving license, or credit card of Facebook users. This naming policy of Facebook has prohibited names that are prone to judgemental elements, such as names that contain too many words, excessive capital letters, or first names that have initials. The Facebook accounts that have such names will be detected and thus suspended by the monitor software of Facebook [18]. However, the real-name policy maintained by Facebook has raised safety concerns on the privacy and data protection of Facebook users. This situation is due to the reason that one's real name often reflects some identities and cultures. The real name of some people may also contain many potentially sensitive details that might be obtained by people with bad intentions while browsing their Facebook profiles [19]. With the rising privacy demands in the surveillance society, some Facebook users started to protest against this real-name policy which causes Facebook to relax the real names requirement to "provide the name they use in real life" [20]. Despite the real name issue, some argue that real name is crucial to establish the trustworthiness of the apps [21].

Nevertheless, as privacy and safety issues have received more weight in interest-based groups, the anonymity feature becomes more attractive than trustworthiness. Socializing within the interest-based groups that do not require their members to provide their real identities is a desired characteristic of a social app for some people. Besides, due to the disinhibition effect of being anonymous, people tend to loosen up and share personal things about themselves. They may reveal their wishes, fears, or secret emotions when they can separate what they express from their real identity and their natural world. Anonymity gives them more courage to say and speak more openly. Everyone has an equal opportunity to express their mind regardless of their race, gender, or status in the real world [22]. Privacy and secrecy issues also have been highlighted in mobile apps/systems in education and business domains [23], [24]. In 2017 a survey on awareness of privacy has been conducted among Android users, which revealed that the level of understanding is still low [25] even though there is a raising need for privacy.

Caution must be taken as the true negative self that is usually hidden in the physical world may no longer be hidden in anonymous social media platforms [12]. Should there be any user with negative minds and intentions, they can quickly spread inappropriate or unhealthy information. Thus, a feedback or reporting feature should be added to this apps to lodge a report about any inappropriate behavior of its members. As little in known on the need of reporting feature and on how perception of the importance of interest group relates to the perception of the anonymity feature these are the research gaps addressed by this paper.

\section{METHODOLOGY}

This section will describe how we answer the research questions as stated earlier in Section I. An explanatory approach has been adopted for market segment analysis to observe the anonymity feature in Android apps worldwide. In particular, we adopted the quantitative observation method 
which is usually adopted in studying market segments for marketing purposes such as in [26], [27].

A quantitative approach has been adopted in a pilot study to determine the relationship between the interest-based and anonymity features, especially among Malaysian users. Descriptive statistical analysis is adopted to analyze the result of questionnaire responses. IBM SPSS software, version 2, was used to perform the statistical analysis and for data screening (error and missing values checking). A pilot study is a part of our full-scale project that aims to determine the potential of anonymity features in mobile apps development for Malaysian interest-based groups.

\section{A. Research on Market Segment}

To answer the first research question, we use Google Play Store to find inter-est-based group apps on the Android platform. As we set English as the apps' language, apps in other languages such as Chinese, Japanese, and Korean are excluded. The apps with invitation links and software bugs are also excluded from this study as they cannot be accessed quickly during the research phase.

After filtering all of the apps, we further analyze them by conducting a member registration process. Unlike the mobile apps reported in [28], not all app providers reveal the anonymity feature in their apps. Thus, registration of a new member account is performed. This process is crucial to check the anonymity features within the apps by experiencing an actual registration process. In this study, we perform binary classification. Apps requiring a real name or actual information (such as the mobile phone number) are classified as apps without anonymity. In contrast, apps allow the member to be anonymous as apps with anonymity.

We also observed the criteria of whether the app offers a single-interest group or multiple-interest groups. Apps that serve one main topic but with multiple groups are classified as multiple-interest groups. For example, an app focuses on drawing art as the main topic with multiple groups such as the water-color community, oil painting community, and sketch community. A market segment analysis of this quantitative observation study will be reported in Section IV.

\section{B. Questionnaire Development}

A questionnaire has been designed based on samples of best practices of online questionnaires related to mobile apps usability and UX [29]-[31]. The questionnaire is divided into three categories: demographic, mobile user experience, and preference. The demographic category consists of three items, namely gender, age, and nationality; mobile usage experience has four items where respondents will tell whether they have experience with interest group apps and the anonymity feature. The preference category consists of nine items. The first two categories consist of close-ended questions, while the third category has five closed-ended questions (Yes/No and fivescale Likert-chart questions) and four open-ended questions. The questionnaire is developed using an online Google form, as shown in Fig. 1.

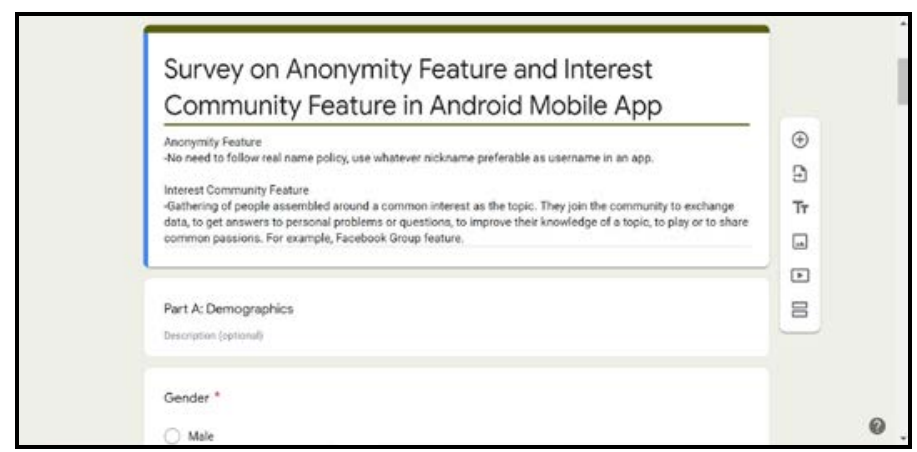

Fig. 1. The Online Questionnaire.

We utilize Facebook's interest-based group to distribute the questionnaire as it is the most popular social media platform to date. In particular, we use a public Facebook group called “Thesis / Survey Questionnaire Filling Group" with 14.0K members and a private group called "Student Survey Exchange" with $13.8 \mathrm{~K}$ members. Both groups facilitate their member worldwide in getting the respondents for research surveys that are based on mutual collaboration and voluntary basis. The members mainly gather in this group to collect responses for their surveys. To exchange for the responses from other members, they are required to help other group members to fill up their questionnaires or do their surveys. A call for the survey is made in the group posting, as shown in Fig. 2. Even though the focus of the pilot study is Malaysian users, we also record responses from other countries that took part in the survey. We set to observe if non-Malaysians show common or different characteristics from Malaysians. In this pilot study, we allow the respondents to answer the questionnaire within seven days before collecting the results.

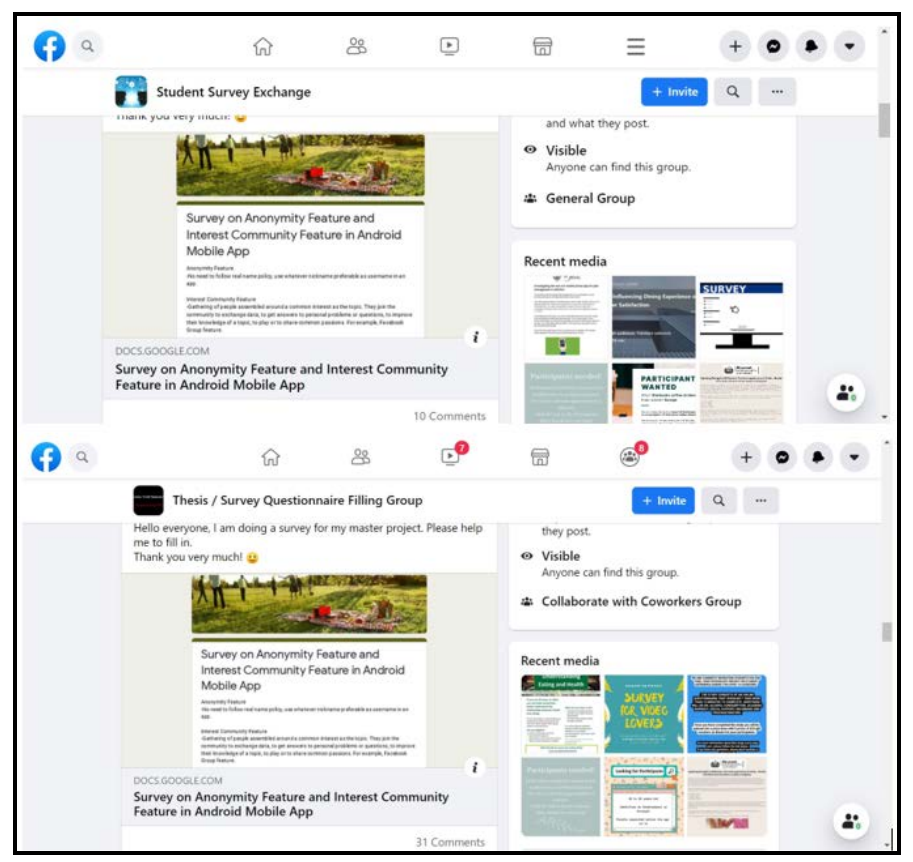

Fig. 2. Posting on the Call for the Survey. 


\section{RESULTS AND DISCUSSION}

\section{A. Market Segment Analysis}

In this section, the results of market segment analysis using descriptive statistics will be presented. A set of interest-based Android apps $(n=65)$ have been selected from the Google Play Store, as shown in the Appendix. These apps belong to interest group categories such as social, gaming, communication, and art.

The top pie chart in Fig. 3(a) shows that apps that offer anonymous features dominate the Android apps market segment by $69 \%$. In contrast, Fig. 3(b) shows that most of the apps understudy offers multiple interest groups, with $68 \%$ of the market segment.

To analyze further, we seek to examine the number of apps with (and without) anonymity features by interest group types. As shown in Fig. 4, it has been found that the apps with the anonymity feature offer more multiple interest group creation than the apps without the feature, with $43 \%$. Only $23 \%$ of the apps without anonymity feature offer multiple interest group creation.

Based on the results presented so far, we can see that most Android apps provider are ready to give options for their users to be anonymous or not. As a result, these kinds of apps dominate the Android apps market segment. The results also indicate the popularity of multiple interest group creation within a single app regardless of whether it comes along the anonymity feature or not.

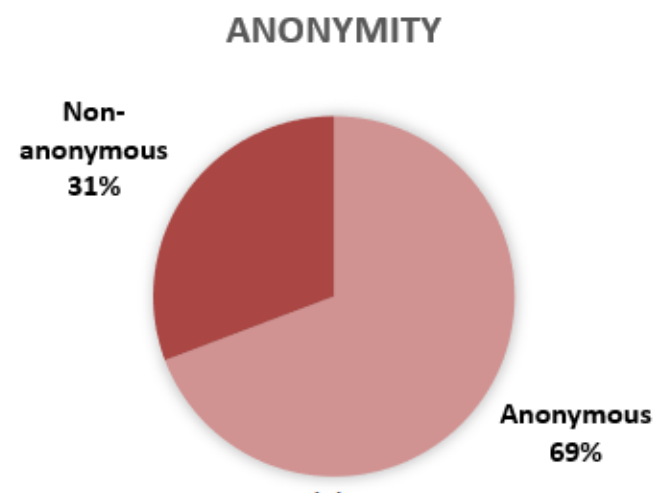

(a)

\section{INTEREST GROUP}

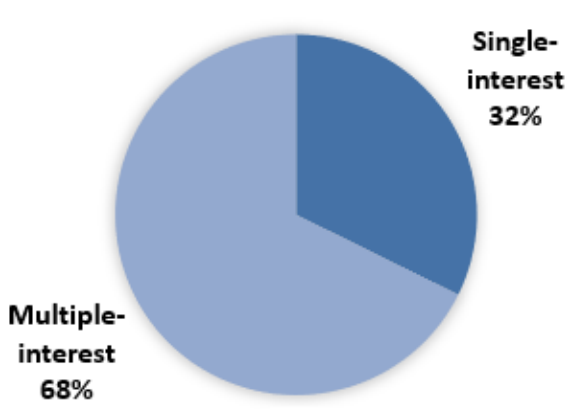

(b)

Fig. 3. (a)The Proportion of Android Apps based on Anonymity, (b) the Proportion of Android Apps based on the Type of Interest Group.

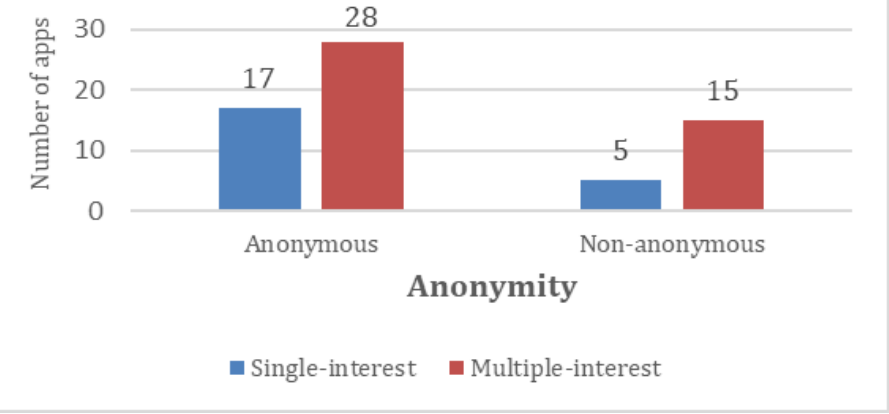

Fig. 4. The Proportion of the Interest Group Type by the Anonymity Type.

\section{B. Close-Ended Question Responses Analysis}

Data collection was facilitated via Facebook interest groups, as mentioned earlier in Section 3.0, where 34 responses $(n=34)$ were received from Android app users. Table I shows the demographic information of the participants.

Table II consists of the results retrieved from the Experience category items that cover questions regarding the experience of users with interest groups and anonymity features. The results show that, in terms of age group, those within 18-24 years old are more familiar with interest groups app and apps with anonymity features as compared to those from 25-34 age category. We can say that respondents who use these apps are among the early adults based on their age range. It is also found that female dominates both, apps with interest groups and with anonymity features. $44 \%$ of Malaysian have experience with group interest apps, and $41.2 \%$ of them also used apps with anonymity features before. If we accumulate the scores for non-Malaysian, we can also see most of the respondents already exposed to the group interest apps and apps with anonymity features.

TABLE I. DEMOGRAPHIC INFORMATION OF THE PARTICIPANTS

\begin{tabular}{|l|l|}
\hline Characteristic & Value \\
\hline Age (years), n (\%) & \\
\hline $18-24$ & $19(55.9)$ \\
\hline $25-34$ & $15(44.1)$ \\
\hline Gender, n (\%) & \\
\hline Female & $21(61.8)$ \\
\hline Male & $13(38.2)$ \\
\hline Country, n (\%) & \\
\hline Austria & $1(2.9)$ \\
\hline British & $2(5.9)$ \\
\hline Brunei & $1(2.9)$ \\
\hline Egyptian & $1(2.9)$ \\
\hline Indian & $3(8.8)$ \\
\hline Kenyan & $1(2.9)$ \\
\hline Malaysian & $16(47.1)$ \\
\hline Maltese & $1(2.9)$ \\
\hline Pakistani & $5(14.7)$ \\
\hline Singaporean & $2(5.9)$ \\
\hline Swiss & $1(2.9)$ \\
\hline
\end{tabular}


TABLE II. THE RESULTS OF CLOSED-ENDED ITEMS IN THE EXPERIENCE CATEGORY

\begin{tabular}{|l|l|l|l|l|}
\hline & \multicolumn{2}{|l|}{$\begin{array}{l}\text { Have you used apps with } \\
\text { interest groups before? } \\
\text { Characteristic }\end{array}$} & \multicolumn{2}{l|}{$\begin{array}{l}\text { Have you used apps } \\
\text { with anonymity } \\
\text { features before? (\%) }\end{array}$} \\
\hline & Yes & No & Yes & No \\
\hline Age (years) & & & & \\
\hline $18-24$ & 44.1 & 11.8 & 47.1 & 8.8 \\
\hline 25-34 & 41.2 & 2.9 & 41.2 & 2.9 \\
\hline Gender & & & & \\
\hline Female & 50.0 & 11.8 & 52.9 & 8.8 \\
\hline Male & 35.3 & 2.9 & 35.3 & 2.9 \\
\hline Country & & & & \\
\hline Austria & 2.9 & 0.0 & 2.9 & 0.0 \\
\hline British & 5.9 & 0.0 & 2.9 & 2.9 \\
\hline Brunei & 2.9 & 0.0 & 2.9 & 0.0 \\
\hline Egyptian & 2.9 & 0.0 & 2.9 & 0.0 \\
\hline Indian & 5.9 & 2.9 & 8.8 & 0.0 \\
\hline Kenyan & 2.9 & 0.0 & 2.9 & 0.0 \\
\hline Malaysian & 44.1 & 2.9 & 41.2 & 5.9 \\
\hline Maltese & 0.0 & 2.9 & 0.0 & 2.9 \\
\hline Pakistani & 11.8 & 2.9 & 14.7 & 0.0 \\
\hline Singaporean & 2.9 & 2.9 & 5.9 & 0.0 \\
\hline Swiss & 2.9 & 0.0 & 2.9 & \\
\hline
\end{tabular}

Table III consists of the results retrieved from the closeended question items in the Preference category. In this category, respondents state their preference regarding apps with an interest group and anonymity feature and the type of interest group. The results show that most respondents prefer apps with interest groups and anonymity features, in which female users and those from 18-24 years old dominate the score. Respondents from the same categories also show the highest preference on multiple interest groups than the singleinterest group. The findings also reveal that most Malaysian prefer apps with interest groups and anonymity features. The same behavior also can be seen among non-Malaysian. Nevertheless, in terms of groups, Malaysians equally prefer the single and multiple interest groups, while non-Malaysians show more interest in the multiple groups' apps.

To examine the relationship between one's perception of the importance of apps with interest groups and anonymity features, we extract the responses from the five-scale Likertchart questions in the Preference category. The questions require the respondents to rate the importance of apps with interest groups and anonymity features from 1 (the least important) to 5 (the most important).

Fig. 5 illustrates the Scatterplot graph that shows the distribution of users based on the rating on the importance of interest groups and anonymity features. If we divide the chart equally into four quadrants, we can see that most users are grouped at the top right quadrant, where a high rating was given to the importance of both interest and anonymity features. However, four respondents who value the importance of interest groups do not have the same opinion on the importance of the anonymity feature (11.76\%). Only one respondent who gives a high rating on the anonymity feature gives a low rating on the importance of the interest group. As the left bottom quadrant is empty, we can say none of the respondents think less about the importance of the interest group and the anonymity features.

TABLE III. THE RESUlts OF CLOSED-ENDED ITEMS IN THE PREFERENCE CATEGORY

\begin{tabular}{|l|l|l|l|l|l|l|}
\hline Characteristic & \multicolumn{2}{|l}{$\begin{array}{l}\text { Do you prefer } \\
\text { apps with an } \\
\text { interest } \\
\text { group? }\end{array}$} & $\begin{array}{l}\text { Do you prefer } \\
\text { apps with an } \\
\text { anonymity } \\
\text { feature? }\end{array}$ & \multicolumn{2}{l|}{$\begin{array}{l}\text { Type of preferred } \\
\text { interest group } \\
\text { apps }\end{array}$} \\
\hline Yes & No & Yes & No & Single & Multiple \\
\hline Age (years) & & & & & & \\
\hline 18-24 & 50.0 & 5.9 & 44.1 & 17.6 & 14.7 & 41.2 \\
\hline 25-34 & 41.2 & 2.9 & 38.2 & 0.0 & 20.6 & 23.5 \\
\hline Gender & & & & & & \\
\hline Female & 55.9 & 5.9 & 50.0 & 11.8 & 14.7 & 47.1 \\
\hline Male & 35.3 & 2.9 & 32.4 & 0.0 & 20.6 & 17.6 \\
\hline Country & & & & & & \\
\hline Austria & 0.0 & 2.9 & 0.0 & 2.9 & 0.0 & 2.9 \\
\hline British & 5.9 & 0.0 & 2.9 & 2.9 & 2.9 & 2.9 \\
\hline Brunei & 2.9 & 0.0 & 2.9 & 0.0 & 0.0 & 2.9 \\
\hline Egyptian & 2.9 & 0.0 & 0.0 & 2.9 & 0.0 & 2.9 \\
\hline Indian & 8.8 & 0.0 & 8.8 & 0.0 & 0.0 & 8.8 \\
\hline Kenyan & 2.9 & 0.0 & 2.9 & 0.0 & 0.0 & 2.9 \\
\hline Malaysian & 44.1 & 2.9 & 44.1 & 2.9 & 23.5 & 23.5 \\
\hline Maltese & 0.0 & 2.9 & 2.9 & 0.0 & 2.9 & 0.0 \\
\hline Pakistani & 14.7 & 0.0 & 8.8 & 5.9 & 8.8 & 5.9 \\
\hline Singaporean & 5.9 & 0.0 & 5.9 & 0.0 & 0.0 & 5.9 \\
\hline Swiss & 2.9 & 0.0 & 2.9 & 0.0 & 0.0 & 2.9 \\
\hline & & & & & & \\
\hline
\end{tabular}

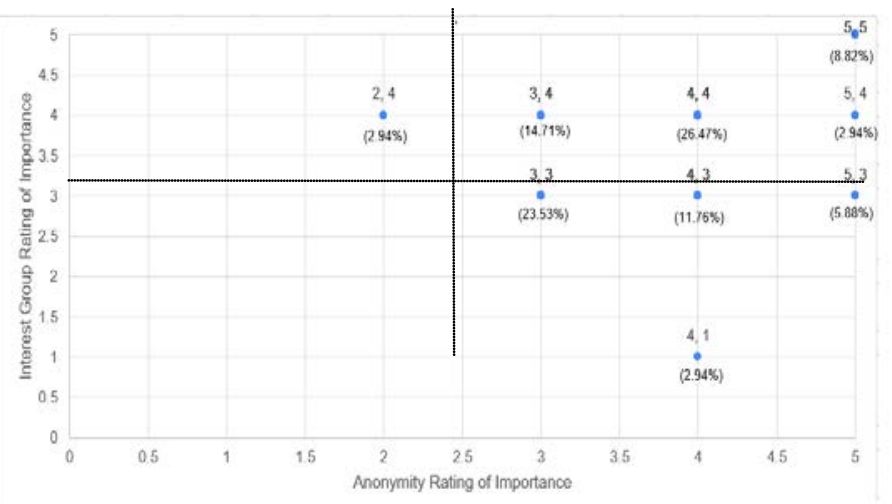

Fig. 5. The Distribution of Users on the Rating on the Importance of Interest Groups and Anonymity Features. 


\section{Open-Ended Question Responses Analysis}

The responses to the open-ended questions from the Preference category allow the participant to express their opinion regarding the rating they give on the importance of interest group and anonymity feature and the type of interest group they prefer. According to some of the responses collected, most participants think that the interest group is important because this feature increases the possibility of meeting people with similar interests and helps introverts discover people with the same interest. Some think that it is nice to post or communicate with others with similar topics and interests and get valuable and specific topic information. Some of the respondents who prefer the multiple-interest group over the single-interest group mentioned that the multiple-interest group allows more options, more choices, and more possibilities to find groups that match their interests. They think that the group will enable people to exchange ideas and thoughts about the shared passion and receive more information. One of the respondents mentioned that the group helps make the mobile phone more organized as the number of applications installed can be minimized.

However, some respondents prefer the single-interest group over the multiple-interest type. A female respondent mentioned that "I don't like to mix up all the interest community in a single app. I tend to categorize the social apps so that I can know that these certain apps are aimed for which community". A respondent who does not favor the interest groups mentioned that "I have less willingness to come together to address issues and have no commitment to deliver ideas."

Those who favor the anonymity feature stated that they think the feature helps in privacy and security aspects and makes them feel safer. They mentioned that the anonymity feature is essential as it can improve internal communications. The feature also enables people to communicate with strangers anonymously through their smartphones when they are unwilling to disclose their real names to the public or people not so close to them. They also suggested that users be given more options to hide their identity and that there should be more options to be anonymous on different applications. A female respondent says that "The interest groups feature in mobile apps allow users to be anonymous for more honesty, openness, and diversity of opinion, meanwhile encourage expressiveness and interaction among users.”.

Some respondents also suggested that a real name is required for identity verification but only shows the username in the application. A male respondent who likes the anonymity feature mentioned that "Even though anonymity feature is preferable, the authority should have some form of access to a small portion of users' data like age and name to avoid any illegal behavior and the application users have to know about it.”

The results yielded from the questionnaires in the pilot study imply the on-demand characteristics of the mobile apps market, especially for Android users. The market segment analysis shows the readiness of the apps providers in terms of providing interest groups (single/multi groups) with anonymity features. As for Malaysian users, the anonymity feature is highly desirable for interest group apps, but there is no difference in their preference in the type of interest group. Nevertheless, as Malaysia is a multi-racial country, we discovered that a better understanding of the categories of the interest-based apps with anonymity features favored by Malaysians (races/ethnicity) could be gained if the questionnaires include questions regarding this topic. A similar improvement can also be made on the market segment analysis of the mobile apps.

\section{CONCLUSIONS}

In conclusion, we have approached anonymity features in mobile apps interest groups using an explanatory, quantitative approach in a pilot study. Within the scope of the research presented in this paper, the results support our hypothesis that mobile apps users' who highly value interest groups will also highly appreciate the anonymity feature provided in the interest groups. The study has allowed us to provide three implications for mobile apps design: including the anonymity feature and interest groups, considering the multi-interest groups in a single app, and the need to embed fair security aspects when the anonymity feature is activated. Even though they are preliminary, the results of this pilot study are adequate for us to proceed with wider audiences (i.e., more age groups, nationality). They need to be validated using representative research or similar case studies in different contexts. Also, the scope of this research is limited to the Android platform. Thus, the results of the study cannot be used to represent other platforms. However, the results could open new research ideas and the design of focused mobile apps. Research that looks at the security feature of mobile apps with anonymity will contribute to a broader understanding of the subject. Such a study could consider such questions as "How can we embed the acceptable security aspect of mobile apps that allow anonymous users?”

\section{ACKNOWLEDGMENT}

We would like to thank the Fakulti Teknologi Maklumat Dan Komunikasi, Universiti Teknikal Malaysia Melaka (UTeM) for supporting this research. This work is under research grant PJP/2020/FTMK/PP/S01771.

\section{REFERENCES}

[1] A. Rosales and M. Fernández-Ardèvol, "Smartphones, apps and older people's interests: From a generational perspective,” in Proceedings of the 18th International Conference on Human-Computer Interaction with Mobile Devices and Services, MobileHCI 2016, 2016.

[2] K. Matthews, "6 Tools to Find Awesome People with Similar Interests," makeuseof.com, 2015. https://www.makeuseof.com/tag/6-tools-findawesome-people-similar-interests/.

[3] L. Martin, "Facebook Ad Targeting: How to Use Interest Groups," Lightning AI, 2019. https://blog.lightningai.com/facebook-ad-targetinghow-to-use-interest-groups-1ec7dcc9d04a.

[4] X. Ma, J. Hancock, and M. Naaman, "Anonymity, intimacy and selfdisclosure in social media," in Conference on Human Factors in Computing Systems - Proceedings, 2016, doi: 10.1145/2858036.2858414.

[5] A. Vasilateanu and C. Casaru, “Anonimity in Health-oriented Social Networks,” in Procedia Computer Science, 2015.

[6] T. Wright, "Security, privacy, and anonymity,” XRDS Crossroads, ACM Mag. Students, 2004.

[7] S. K. T. Febriana and Fajrianthi, "Cyber Incivility Perpetrator: The Influenced of Dissociative Anonymity, Invisibility, Asychronicity, and Dissociative Imagination," in Journal of Physics: Conference Series, 2019. 
[8] C. Piao and X. Li, "Privacy Preserving-Based Recommendation Service Model of Mobile Commerce and Anonymity Algorithm,” in Proceedings - 12th IEEE International Conference on E-Business Engineering, ICEBE 2015, 2015.

[9] C. Denzil, A. S. Leandro, M. Mainack, B. Fabrício, and P. G. Krishna, "The many shades of anonymity: Characterizing anonymous social media content," in Proceedings of the 9th International Conference on Web and Social Media, ICWSM 2015, 2015, pp. 71-80.

[10] D. Bulatovych, "How to Build a Successful Anonymous Social Networking App,” Yalantis.com, 2019. https://yalantis.com/blog/anonymous-social-network-development/.

[11] A. L. Forest and J. V. Wood, "When social networking is not working: Individuals with low self-esteem recognize but do not reap the benefits of self-disclosure on facebook,” Psychol. Sci., 2012.

[12] C. Hu, S. Kumar, J. Huang, and K. Ratnavelu, "Disinhibition of negative true self for identity reconstructions in cyberspace: Advancing selfdiscrepancy theory for virtual setting,” PLoS One, 2017.

[13] J. Suler, “The online disinhibition effect,” Cyberpsychology Behav., vol. 7, no. 3, pp. 321-326, Jun. 2004.

[14] M. Iqbal, “App Download and Usage Statistics (2020),” BusinessofApps, 2020. https://www.businessofapps.com/data/app-statistics/

[15] H. Nurhayati-Wolff, "Social media users as a percentage of the total population Malaysia 2021,” statistica.com, 2021. https://www.statista.com/statistics/883712/malaysia-social-mediapenetration/\#: :text=Facebook's popularity in Malaysia, social media users in Malaysia.

[16] A. Gotter, "Everything You Need to Know About Facebook Groups Marketing," Adespresso.com, https://adespresso.com/blog/facebook-groups-everything-you-needknow/.

[17] E. Moreau, "Everything You Need to Know About Facebook Groups,” lifewire.com, 2020. https://www.lifewire.com/facebook-groups-4103720.

[18] E. Grinberg, “Facebook’ real name’ policy stirs questions around identity,” CNN, 2014. https://edition.cnn.com/2014/09/16/living/facebook-namepolicy/index.html.

[19] S.-L. Chen, "What's In A Name? - Facebook’s Real Name Policy And User Privacy,” Kansas J. Law Public Policy’s, vol. 28, no. 1, pp. 146172, 2019, Accessed: Mar. 11, 2021. [Online]. Available: https://lawjournal.ku.edu/wpcontent/uploads/2019/08/V28_I1_05_Chen_Web.pdf.
[20] CBC News, "Facebook makes changes to 'real names' policy after complaints,” cbc.ca, 2018. https://www.cbc.ca/news/technology/facebook-real-names-

1.3367403\#: :text=Technology \%26 Science-,Facebook makes changes to "real names" policy after complaints,to have their accounts suspended.

[21] A. M. Cirucci, "Facebook's affordances, visible culture, and antianonymity,” in ACM International Conference Proceeding Series, 2015, doi: 10.1145/2789187.2789202.

[22] J. Suler, “The online disinhibition effect,” Cyberpsychology and Behavior. 2004.

[23] C.-H. Lai, B.-S. Jong, Y.-T. Hsia, and C. Yuan, "Paper-Use of a Mobile Anonymous Question-Raising System to Assist Flipped-Classroom Learning Use of a Mobile Anonymous Question-Raising System to Assist Flipped-Classroom Learning,” Int. J. Interact. Mob. Technol., vol. 14, no. 03, pp. 66-81, Feb. 2020.

[24] B. Jagdale and J. Bakal, "Privacy aware monitoring of mobile users in sensor networks environment,” Int. J. Interact. Mob. Technol., vol. 13, no. 2, pp. 127-140, 2019.

[25] M. M. Alani, “Android Users Privacy Awareness Survey,” Int. J. Interact. Mob. Technol., vol. 11, no. 3, pp. 130-144, Apr. 2017.

[26] I. Bose and X. Chen, "Quantitative models for direct marketing: A review from systems perspective,” Eur. J. Oper. Res., vol. 195, no. 1, pp. 1-16, May 2009.

[27] D. A. Siegel, "The mystique of numbers: Belief in quantitative approaches to segmentation and persona development," in Conference on Human Factors in Computing Systems - Proceedings, 2010, pp. 47214731.

[28] J. Bolluyt, "20 Android and iOS Apps to Give You Privacy and Anonymity,” cheatsheet.com, 2014. https:/www.cheatsheet.com/technology/20-android-and-ios-apps-to-giveyou-privacy-and-anonymity.html/.

[29] Lulu, “14 Important UX Questions to Include in Your Mobile Application Survey,” UX design.cc, 2019. https://uxdesign.cc/14important-ux-questions-to-include-in-your-mobile-application-surveyb1e094c2620c.

[30] Delighted, “Mobile app surveys: Best practices and sample questions," delighted.com, 2020. https://delighted.com/blog/mobile-app-survey-bestpractices.

[31] Michael Litwin, "Mobile App Survey: Complete Guide with Question Examples,” https://survicate.com/, 2018. https://survicate.com/mobileapp-survey/mobile-app-survey-questions/. 
APPENDIX

\begin{tabular}{|c|c|c|c|c|c|c|c|c|}
\hline No & App Name & Logo & No & App Name & Loso & No & App Name & Logo \\
\hline 1 & Amino & 31 & 23 & Geek Dating & $\theta 0$ & 45 & Qooiver & gi \\
\hline 2 & Anime & 86 & 24 & GLIDE & (39) & 46 & SHEROES & sMt: \\
\hline 3 & AnimefansBase & $\sqrt{7}$ & 25 & Glostars & 0 & 47 & Solatearn & \\
\hline 4 & Capture & 0 & 26 & Goodwall & $\Delta$ & 48 & Still Active & \\
\hline 5 & Clubify & $S Q$ & 27 & Grasscity Forum & & 49 & Still Active & 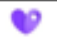 \\
\hline 6 & ComeOut & 둉 & 28 & hi-hive & 8 & 50 & Tandem & 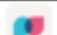 \\
\hline 7 & Comma & 9 & 29 & Hobbinity & (9) & 51 & Tapatalk & \\
\hline 8 & Commune Community & & 30 & iConek Community Hub & PI & 52 & The Mighty & \\
\hline 9 & Community & 6 & 31 & Instagram & 同 & 53 & Topiks & Q \\
\hline 10 & Community & [ & 32 & InterNations & (2) & 54 & Topiks & \\
\hline 11 & Community & & 33 & IQ & & 55 & TUBBR & \\
\hline 12 & Community & c & 34 & KStarLive & & 56 & Tumbir & \\
\hline 13 & Community Café & e & 35 & LMK & LME & 57 & Vent & \\
\hline 14 & DailyAct & (C) & 36 & Lysn & Fe & 58 & Vingle & \\
\hline 15 & Defense News & $\theta$ & 37 & Meetup & (ii) & 59 & We Heart it & \\
\hline 16 & DeviantArt & r & 38 & Meipai & AP & 60 & WEBTOON & 푱 \\
\hline 17 & DogCha! & $\infty$ & 39 & Orbis & *ै & 61 & We Chat & 8 \\
\hline 18 & Doongle & $: 0$ & 40 & Panion & (1) & 62 & Writco & $w$ \\
\hline 19 & Edapt & A & 41 & Photory & P & 63 & Yapper & ant \\
\hline 20 & Facebook & $f$ & 42 & Picsart & (2) & 64 & Youtube & \\
\hline 21 & FAN GURU & 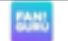 & 43 & Pinterest & $\rho$ & 65 & Zest & $\theta$ \\
\hline 22 & Gamer Community Forum & 5] & 44 & PS Community & 8 & & & \\
\hline
\end{tabular}

